\title{
Cultural Affordances and Social Media
}

\author{
Yinan SUN \\ University of Hawai $i$ at Manoa \\ sunyinan@hawaii.edu
}

\author{
Daniel D. Suthers \\ University of Hawai $i$ at Manoa \\ suthers@hawaii.edu
}

\begin{abstract}
This paper first reviews the development and application of affordances theory in the field of social media studies. Then, it examines the significance and limitations of the original meaning of affordances of the environment that is provided by American psychologist James Gibson. The paper argues that the cultural aspect of affordances has been understated and should be included as part of affordances theory. To enrich theoretical understanding of affordances and further facilitate empirical studies of social media affordances, the paper offers a novel definition of cultural affordances that bridges cultural studies and social media studies. The new definition of cultural affordances includes two layers, which are cultural affordances of technology and affordances of the cultural. Later, the paper provides examples to showcase how this novel definition can be applied in prior empirical studies with a focus on WeChat.
\end{abstract}

\section{Introduction}

More and more research nowadays utilizes the concept of affordances as a theoretical foundation to analyze how social media affects ordinary people's lives. Coined by American psychologist James Gibson [27], the concept of affordances is described as "the affordances of the environment are what it offers the animal, what it provides or furnishes, either for good or ill" (p.127). Based on Gibson's original concept, scholars from multiple disciplines have conceptualized various kinds of affordances $[3,10,11,17,20,24,25$, 33, 38, 42, 64, 66, 70, 73, 78, 82, 93, 94]. Prior studies reveal that a consensus on the definition of affordances does not exist and indiscriminately applying these concepts in the field of social media studies may lead to further confusion and misinterpretation. Among these aforementioned affordances, some concepts (e.g., physical affordances, technology affordances) demonstrate an inclination of technological determinism; some notions show (e.g., social affordances) a tendency of social constructionism; and other ideas (e.g., vernacular affordance, affordances-inpractice) integrate the technological and the social. Yet, they either exclude or downplay cultural factors when developing the theory of affordances. The term cultural affordances has been introduced in the fields of philosophy and HCI. Yet, a theoretical understanding of affordances with a focus on the cultural aspects in the field of social media studies is still underdeveloped. Hence, this paper aims to fill the theoretical vacuum by offering a new definition of cultural affordances that assembles culture and social media platforms and reveals the power dynamics that are embodied through social media affordances.

This theoretical paper is divided into four sections. The first section outlines prior studies on social media affordances. The second section examines the significance and limitations of Gibson's affordances of the environment. The third section provides a novel approach to social media affordances and a different definition of cultural affordances from the perspective of cultural studies. The last section uses prior empirical studies to exemplify the new definition of cultural affordances.

\section{Social Media Affordances: Divergence and Convergence}

\subsection{Platform-centered Social Media Affordance}

Prior studies of affordances of ICTs demonstrate a tendency to centralize properties of a technology and focus on how it affects social interaction [37, 38, 93]. Gaver [25] defines technology affordances as independent, inherent, and physical properties of an object that are compatible with a user for possible action. Wellman et al. [94] states that affordances of the Internet, such as boarder bandwidth, portability, connectivity, facilitate networked individualism. Kreijin [46] states that social affordances are properties in a computer-mediated environment that facilitates learners' social interaction. Research demonstrates the same inclination when developing the theory of affordances in the field of social media studies. Graves [26] claims that read input, fixity and juxtaposition are the affordances of blogging, which have "a democratizing influence ... making journalists more accountable to their audiences" (p.344). boyd [10] argues that networked technology inducts structural 
affordances of networked publics, which are persistence, replicability, scalability, and searchability. It can "destabilize core assumptions people make when engaging in social life" and "play a powerful role in controlling information and configuring interaction" [10, p.46]. Treem and Leonardi [83] claim that organizational use of social media reveals four unique affordances of social media, which are visibility, persistence, editability, and association. These distinguished affordances can alter ways of socializing, sharing knowledge, and possessing power [83]. Vitak and Kim [90] state that social media affordances afford users to share and consume information at a lower cost and in less time. Trepete [84] defines affordances as "social media functions" (p.1), which solicit users to take certain actions accordingly, such as commenting, uploading contents, and tagging friends. Bareither and Bareither [3] propose the notion of emotional affordances of digital media as "its capacities to enable, prompt and restrict the enactment of particular emotional experiences unfolding in between the media technology and an actor's practical sense for its user" (p.15). Even though these analyses do not state that technological features determine social practices, they concentrate on how social media platforms affect people's interaction. This platform-centered approach to affordances fails to include the diverse and constantly evolving relations between users and platforms; it overlooks the social and cultural contexts [17].

\subsection{User-centered Social Media Affordances}

In contrast, some scholars place users' needs as the center and state the affordances of a group of people can encourage certain ways of using ICTs while discouraging others $[11,78]$. Bradner [11] points out that social norms of a community are crucial in terms of whether or not a technology-mediated social interaction is enacted. Schrock [78] defines communicative affordances of mobile media as "an interaction between subjective perceptions of utility and objective qualities of the technology" and perceptions of utility are affected by social norms and contextual understandings (p.1238). Along the same lines, several studies on social media affordances focus on how users proactively utilize social media platforms to fulfill their needs. Gibbs, Rozaidi and Eisenberg [28] report that while social media could encourage information sharing and openness, users also manipulate social media affordances to "limit their accessibility to others, their attention to incoming messages, and the knowledge they shared" (p.114). Nagy and Neff [64] introduce three types of imagined affordances: 1) the imagined unanimous understanding about affordances, 2) the imagination about affordances by users and designers, and 3) affordances imagined as something static and dependent on humans' action. Among the three types, affordances are by and large "imagined by users" [64, p.1]. McVeigh-Schultz and Baym [56] propose the notion of vernacular affordance as "unfolding relationships, emergent practices and sense-making processes" (p.2). Users can invent new practices and rules that are unanticipated by designers as it goes along with their own sense [56].

Social affordances of technology concentrate on social media platforms that offer novel social interactions. Social affordances of a group of people emphasize how users employ social media platforms to fulfill their needs and goals. This divergence indicates a departure from Gibson's original idea of affordances that endeavors to overcome the subjective-objective binary view.

\subsection{Integrating the Technological and the Social}

To bridge the gap between the technological and the social, several scholars develop the theory of affordances by integrating the technological features and the social factors. Influenced by Orlikowski's concept of technologies-in-practice [69], Fayard and Weeks [24] combine the concept of affordances and Bourdieu's notion of habitus [9] and propose the notion of affordances for practice as "both dispositional and relational and that focuses on the practice in which technology is used rather than on technology features" (p.241). A habitus is formed through the objective economic and social conditions, and these conditions make certain thoughts and behaviors more desirable [9]. The notion of affordances for practice integrates "the social and physical construction of technology, and the material environment" as well as "the social and symbolic structures" [24, p.247]. Nonetheless, it downplays cultural factors as the outcome of social and economic conditions. Postigo [72] suggests that social media platforms like YouTube are technological platforms that offer both technological affordances and social affordances. Technological affordances are "the set of functions that a technology makes possible" and social affordances are "the social structures that take shape in association with a given technical structure" [72, pp. 4-5]. These two affordances work together to fulfill users' needs and YouTube's business interest [72]. Yet, Postigo's understanding of affordances is still platform-centered and the discussion of cultural aspects of affordances is missing.

Also inspired by the concept of technologies-inpractice [69], Costa [17] proposes the notion of affordances-in-practice, which means "the enactment of platform properties by specific users within social and 
cultural contexts" (p. 3651). This definition emphasizes users' agency, ongoing process, and particular material, social and cultural contexts and avoids theoretical reductionism [17]. Based on her empirical study, Costa [17] points out that structural affordances [10] and the phenomenon of context collapse [53] are not found in a non-Western context. Hence, social media affordances are "not fixed and stable properties of social media..., which may radically vary across social and cultural contexts" [17, p. 3651]. The notion of affordances-inpractice disapproves of the prevailing understanding of affordances as something stable and invariant and the dominant platform-centered approach, instead including social and cultural aspects in the concept of affordances. Yet, simply involving all technological, social, and cultural aspects in the concept of affordances is not enough.

Prior studies of social media affordances depart from the original concept and inadequately explain how various aspects of affordances interact with each other and why users select certain affordances rather than others. Meanwhile, it is still unclear why cultural factors have been either excluded from or downplayed in the theory of affordances. Hence, we need to revisit the original meaning of affordances.

\section{Revisiting Gibson's Affordances}

\subsection{The Significance of Gibson's Affordances of the Environment}

In his book the Ecological Approach to Visual Perception, Gibson [27] defines the affordances of the environment as what the environment could offer to humans and animals. This statement is significant in at least two ways. Firstly, it aims to transcend the subjective-objective dichotomous view and perceives humans and animals and their situated environment as complementarity through possible relations. According to Gibson, an external tool becomes a part of a user's body when it is attached to the user's hand, and the tool becomes a part of the environment later when it is detached from the hand. Hence, "the absolute duality of 'objective' and 'subjective' is false" [27, p.41]. Influenced by Gibson's perspective, Norman [67] defines affordances as the relationship between the properties of an object and the capabilities of an agent: a chair affords support and sitting, a glass affords transparency and seeing through, and a knob affords turning and pushing. In the same line, Van Osch and Mendelson [89] describe affordances as interactions among developers, users, and an artifact. Treem and Leonardi [83] points out that social media affordances (e.g., visibility) are formed in relationships between people and the feature of a technological artifact.

Secondly, it endeavors to free people from the bondage of "mediated or indirect" knowledge or "knowledge at second hand" that could potentially limit people's ways of thinking and doing [27, p.42]. For Gibson, "the 'values' and 'meanings' of things in the environment can be directly perceived" (p. 127). Hence, knowing affordances should start from directly perceiving an object under the ambient optical array rather than through mediated second-hand knowledge such as "images and writing" or "the past experiences and memory" [27, pp. 42, 254]. Impacted by Gibson's direct learning and first-hand knowledge, scholars in the field of information systems developed a realist ontology of affordance and suggested that affordances can be perceived directly [76, 106]. Norman [67] proposes the concept of perceived affordances as strong clues or signals for action. Gaver [25] contends that "common examples of affordances refer to perceptible affordances, in which there is perceptual information available for an existing affordance", for example, water affords drinking, a ball affords throwing (p. 80). Hartson [33] introduces cognitive affordances as design features that facilitate users in knowing, physical affordances as design features that help users in doing, sensory affordances as design features that improve sensing, and functional affordances as design features that support users in accomplishing their work. Based on Norman's perceived affordances, Zhao et al. [104] introduce four types of perceived affordances of social media and contends that they are attributes of information technology artifacts that can be either physically, cognitively, or emotionally manipulated or sensed by users.

\subsection{Limitations of Gibson's Affordances of the Environment}

Despite its significance, Gibson's theory of affordance is not flawless. Firstly, Gibson disregards that humans and animals could provide affordances to their natural environment and the cultural environment as well as overlooks that what they could offer are influenced by cultural values and meanings. For Gibson [27], humans and animals can offer various affordances to other animals and people. Yet, he refrains from mentioning that humans and animals could offer something back to the environment. This omission might be due to his restricted view about the environment as static and lacking agency. To overcome this restricted view, the notion of agency should be extended in at least two ways: first, the environment is neither static nor nonresponsive and it has agency; second, having agency is to maintain a relationship 
through an on-going process rather than through possessing an absolute power to complete something [81]. Likewise, Despret [19] claims that forests, intestinal bacteria, mushrooms, or soils, have their own agency of being. In his book Down to Earth, Latour [48] states that the assumption of two centers, which are man and nature, is implausible. Rather than saying "we are humans in nature", Latour [48] proposes that "we are terrestrials amid terrestrials" and "this applies to workers as well as to birds in the sky, ... to forests as well as to animals" (pp.86-87). Hence, it can be stated that there is only one environment that evolves all the time, humans and animals are part of it, and the environment is responsive to what humans and animals could offer. Likewise, Zhao et al. [104] point out that social media often provides certain design functions to respond to influential events or topics. Ran et al. [74] propose that WeChat launched new time-limited privacy settings after receiving negative feedback from users. In other words, users and designers are part of a platform, a platform is responsive to what users offer (e.g., posts, feedbacks). What users can offer to a platform are shaped by certain cultural values and meanings.

Secondly, Gibson's description about the affordances of the environment shows an inclination towards the natural world. In other words, the affordances are invariant and offered by the natural environment that is prior to the cultural world [27]. However, his postbox example reveals that the affordance of an object can also be defined by the cultural environment. The affordances of a postbox are defined not only by its size and shape but also by its meaning and values that are established and shared in a particular cultural setting. In addition, Gibson [27] suggests that the affordances that a person could provide are based on what the other could offer (e.g., men and women, buyers and sellers, mothers and children); and the reciprocal relations are "lawful" (p. 135). However, the seemingly lawful reciprocal relations are socially and culturally constructed. Furthermore, Gibson points out that invariant affordances of the environment are relative terms since "permanence is relative. .... Almost nothing is forever permanent" [27, p. 13]. Hence, available affordances could be defined by the natural environment as well as the cultural environment, and the concept of affordances is not one-dimensional. Zammuto et al. [105] point out that affordances include both technology features and salient organizational culture. Bloomfield et al. [8] state that affordances of an object should not be reduced to its material aspects but are inseparably associated with a particular social and historical context. Zheng and $\mathrm{Yu}$ [106] contend that social media affordances are "necessarily "socialized" and direct perception of affordances is shaped by a person's "experiences, skills, and cultural understandings" (p.292). A person from a Western country may not perceive the affordances of chopsticks [106]. In other words, affordances of an object include both the technological and the cultural.

Thirdly, Gibson prioritizes direct knowledge and downplays mediated indirect knowledge that is social and culturally constructed. For Gibson, knowledge includes first-hand knowledge that a person perceives directly and knowledge that are "indirect or mediated" or "knowledge at second", such as "images, pictures, and writing" [27, p.42]. Compared to first-hand knowledge, Gibson [27] argues that second-hand knowledge is less reliable. In contrast, Barker [4] points out that "knowledge is specific to language-games" ( $p$. 229), local-grounded, plural and heterogenous. An overarching understanding of truth or better knowledge does not exist. American philosopher Richard Rorty argues that "knowledge is a matter not of getting a true or objective picture of reality but of learning how best to cope with the world. .... the idea of 'better' refers to a value judgement about the consequences of describing the world in this way" [4, p. 627]. Arguably, Gibson's prioritization of first-hand knowledge only reveals his own value judgment. Moreover, the boundary between first-hand knowledge and second-hand knowledge is never clear cut. On one hand, Gibson [27] suggests that the shape of a toy allows two children to perceive its common affordance. On the other hand, Gibson [27] states that the common affordance of a toy is based on the shared value between the two children. Hence, it can be argued that the common affordances of a toy are an integration of first-hand knowledge (e.g., the shape, the size) and second-hand knowledge (e.g., a gift, something to play with). Likewise, Albrechtsen et al. [1] notice that "sticking to a conviction that affordances are associated with direct perception-action only" is too narrow to explain high-level cognitive issues, such as culture, language, and knowledge. Bærentsen and Trettvik [2] maintain that the direct learning has "an essential cultural-historical component" and the concept should be seen "as a generic concept" that includes directly perceivable affordances that are guided by external features and indirectly perceivable affordances that are signified in symbols, representations and memories (p.59). Hence, knowing affordances involves both first-hand knowledge and second-hand ones. All knowledge is important and prioritizing a certain kind of knowledge is contingent and contextual.

Understanding these abovementioned limitations of Gibson's theory of affordances enables a better development of affordances theory in the field of social media studies with a focus on cultural factors. In the rest of the paper, we primarily discuss a novel approach to social media affordances and offer a new definition of 
cultural affordances. Some notions from other fields will be employed to facilitate our discussion.

\section{Cultural Affordances on Social Media Platforms}

Several scholars in the field of Human-Computer Interaction (HCI) stress cultural contexts in understanding the concept of affordances in their fields $[1,2,21,70,71,88]$. What's more, scholars from psychology and HCI introduce the notion of cultural affordances on their own terms [42, 73, 82, 87]. Turner and Turner [87] state that cultural affordances are features that "arises from the making, using or modifying of the artefact and in doing so endowing it with the values of culture from which it arises" and "can only be recognized by a member of the culture which created it" [87, p.6]. Users perceive cultural affordances base on the objectified and historically developed meanings and values [87]. Ramstead, Veissière, and Kirmayer [73] suggest that there are two types of cultural affordances: 1) natural affordances are possible engagement "with which depends on the exploitation or leveraging by an organism of 'natural information', that is, reliable correlations in its environment", 2) conventional affordances are the possible engagement "with which depends on agents' skillfully leveraging explicit or implicit expectations, norms, conventions, and cooperative social practices in the ability to correctly infer the culturally specific sets of expectations of which they are immersed" (p.3). Kitayama, Mesquita, and Karasawa [42] focus on culture and emotions and describe cultural affordances as the potential of eliciting certain emotions and psychological responses in cultural environments. Solymosi [82] emphasizes cultures and actions and defines cultural affordances as "opportunities for thinking about the past and acting into the future"; they are "symbols, words, images" rather than "merely biological and available for immediate action in the immediately present environment" (pp. 594, 602-603). The abovementioned notions of cultural affordances are inspirational yet insufficient to analyze social media affordances due to the strong tendency of cultural determinism $[42,82]$, the restricted view of culture as conventions [73], the culture-technology binary view [87], or the limited understanding of power dynamics of affordances [82]. Thus, we need a novel approach that can assemble social media platforms and culture as well as reveal the ever-changing power dynamics of social media affordances.

\subsection{A Novel Approach to Affordances from the Perspective of Cultural Studies}

Prior studies show a tendency of treating culture as a subfield of sociology in terms of how ICTs influence people's interaction $[45,47,49,77]$. Yet, the forerunner of cultural studies Gramsci [29] claims that rather than rationalism and economism, culture glues people from all walks of life through so-called common sense at various levels and in different degrees. Besides economic and political struggle, there is a "cultural battle to transform the popular 'mentality' and to diffuse the philosophical innovations which will demonstrate themselves to be 'historically true' to the extent that they become concretely universal" [29, p.663]. Thus, culture should be treated as an equal and independent actor rather than a subfield of sociology. The field of cultural studies is known for its radical interdisciplinarity and contextuality with a focus on ordinary people's everyday life $[4,30,31,35,39,80,86,96,98]$. Meanwhile, it pays attention to "the relations between elements" and "the intersection of all practices in and with one another, skirting the problem of determinacy" and goes beyond consciousness and reaches to the "unconscious structures" that link with ideology and imaginary relation of people $[30$, p. 60-61,66].

Despite the absence of a settled definition, culture is widely understood in the field of cultural studies as an assemblage of all relations and practices that are constantly changing and evolving $[4,30,31,39,81,86$, $98,99]$. William [98] contends that culture is "ordinary" and a "whole way of life" (pp.93). Hall [30, 31] mentions that culture is the sum of all conventional and unconventional social practices and their inter-relations that are grounded in a particular social and historical context. Willis and Willis [99] suggest that culture is "the very material of our daily lives, the bricks and mortar of our most commonplace understanding" (p.186-187). Johnson [39] states that culture is the site of analysis, study, and political critique and intervention. Turner [86] describes culture as "the site where meaning is generated and experienced, becomes a determining, productive field through which social realities are constructed, experienced and interpreted" (p.12). Slack and Wise [81] propose that "culture is a complex set of connections or relations" (p. 126). Barker [4] argues that culture includes "both arts and values, norms and symbolic goods of everyday life. While culture is concerned with tradition and social reproduction, it is also a matter of creativity and change" (p. 47). In other words, scholars from cultural studies emphasize inclusiveness, ordinariness, contingency, network, agency, relation, practice, process, meaning and power.

Rather than perceiving technology either as an objective external drive or a consequence of social action $[5,7,44,51,68]$, researchers from cultural studies see technology as "a relationship" and "a 
connection"[95, p.227], "forms of life " [100, p.3], “an assemblage" [102, p.137], "a cultural form"[97, p. 86], "an articulation" that is a form of connecting different elements as a whole [80, p.488], and "a matrix of complex dominations" [32, p.33]. These descriptions show that the nature of technology is about relation, connection, process, agency and power. It resonates with Heidegger's statement that "the essence of technology is nothing technological" [34, p. 35].

In the field of cultural studies, the perspectives of culture and technology are converging rather than diverging. Technology is "integral to culture" and "integrally connected to the context within which it emerges, is developed, and used" [81, pp. 5, 26]. In addition, cultural theorists contend that relationships and meanings are all contingent, unstable and open to change; they are constituted by practices of ordinary people in a particular historical context $[65,80]$. Hence, the relationship between technology and culture is contingent, and the development of technology is not always constructive [80]. Thus, cultural studies offers a novel approach of studying social media affordances, which could overcome the culture-technology binary view and reveal its power dynamics. Meanwhile, it should be pointed out that culture and technology are complementary, yet, not identical. To further elaborate our idea, we offer a new definition of cultural affordances that aims to integrate the cultural and the technological while avoiding any type of reductionism.

\subsection{A New Definition of Cultural Affordances}

To better utilize the theory of affordances in social media studies, we propose a new definition of cultural affordances: 1) cultural affordances of technology: what technology, designers, or a social media platform could offer to users to either reinforce established cultural values and meanings or to destabilize them, it is contingent and contextual; 2) affordances of the cultural: what an ideology that is holistically and deeply embedded in a community and consciously or subconsciously maintained by community members could provide to affect individuals' ways of doing and thinking, including ways of designing and using technology or a social media platform, it reveals the power dynamics of a network that involves various actors in a particular context.

The first type of cultural affordances follows the established conventions and traditions, the guidance of designers or technology, or the known, hence it examines how technology could shape users' ways of doing and thinking and make them become a part of an enframed order of technology (e.g., what a postbox could offer). The second type of cultural affordances explores the invisible, the ambience: like a fish coming to understand that it lives in water, it pays attention to ways of doing and thinking that we take for granted, reveals the unnoticed and the sub-consciousness or unconsciousness, and identifies the looming norms as well as the unknown. In addition, it uncovers that technologies are certain "forms of life" or ways of life $[100$, p.3], rather than the basic, fundamental or the whole/only way of life.

This new definition of cultural affordances is assembling and revealing. It avoids either cultural hegemony or technology hegemony. There is never one overarching cultural affordance, it is always plural and open to integrate more layers. They can be contradictory and sometimes competing with each other. It connects technology and culture, users and designer, and users and platforms; reveals the limitations of technology and established cultural values and meanings; and reminds us that there is a whole world beyond technology. The foregoing discussion shows that even though the concept of cultural affordances on social media is missing, many scholars have already described it in their own terms.

\section{Literature on Cultural Affordances of Social Media}

Prior studies have examined the relationship between social media and culture $[12,22,23,36,41,53$, $62,75,91,92]$. We argue that many of them are in accordance with the different aspects of our proposed definition of cultural affordances. However, a comprehensive explanation that includes the two aspects of the notion is still missing. Meanwhile, the study of social media affordances in a non-Western context is inadequate $[17,58]$. Hence, to further illustrate our statement, we provide a brief review of prior studies that are in line with different aspects of our proposed cultural affordances with a focus on WeChat, a social media platform that originates and is popular in China.

\subsection{Cultural Affordances of Technology}

Several studies suggest that the features of social media platforms play an important role in terms of maintaining traditional cultural values as well as forming new ones [14, 43, 50, 54, 55, 57, 62]. Exemplifying the first case, Holmes, Balnaves, and Wang [36] argue that WeChat leads Chinese society "towards traditional Chinese values" rather than "Western-style democracy" (p.9). Major attributes of Chinese culture, such as filial piety, social connections/guanxi, reciprocal favors/renqing, face/mianzi, and collectivism, are demonstrated and 
practiced on WeChat through its features, such as the digital red envelope [36]. As a tradition, elders put money in red envelopes and give them to children and unmarried family members and wish them another healthy and safe year during Chinese Lunar Year [101]. Meanwhile, people give red envelopes to express good wishes on many other occasions, such as weddings, birthdays, moving into a new apartment and other special anniversaries [52]. As a replication of the real one, the digital red envelope is very successful: the total payment reaches to 400 million Chinese yuan (USD $\$ 85$ million) via 40 million messages during the 2014 Chinese Lunar New Year [36]. It can be stated that the feature of digital red packet allows a user to practice his/her cultural value of filial piety. Vodanovich, McKenna and Cai [91] claim that Chinese cultural values, which are respect for authority, guanxi/social connection, and keqi/well-mannered politeness, are inherent within the design of WeChat. For example, the owner of a subscription account on WeChat can see the comments from his/her subscribers first and the owner has the right to decide what comments he/she wants to post. This design shows "the cultural attribute of respect for authority" [91, p. 6]. Negro, Balbi, and Bory [63] contend that WeChat's funding company TenCent has a long-termed essential strategy called "Sinicization (Zhongguohua)", which means ways of providing new products with roles and meanings that are inspired by Chinese cultures (p.11). Like other products of Tencent, WeChat "undergoes a process of Sinicization, .... one of the most emblematic recent cases is the success of red envelope" [63].

Meanwhile, WeChat can form new cultural values. Wang and $\mathrm{Gu}$ [92] contend that "three unique features of WeChat, which are Moments, Friends' Circles, and Share to, ensure the privacy and security of information sharing", hence, free dissemination of information and public involvement are enabled on WeChat (p.27). The design of these features let a user decide who can see a post. Once a user posts information on his/her friends' circle, a friend of this user can share this information within his/her own selected group of people without noticing the original poster. Hence, "it is very hard to trace the origin of a post and identify the original poster" [92, p.27]. Two cases, which are the dissemination and discussion of a video report on air pollution and the release of five feminist activists, demonstrate that WeChat could play a crucial part in terms of the enhancement of free information and public discussion [92]. DeLuca, Brunner and Sun [18] claim that the private and exclusive design of WeChat provides a stronger sense of community, and it allows WeChat to function as a constructive space to raise awareness among users, incubate a powerful networked public, direct offline public events and facilitate grassroot
NGOs. Tu [85] suggests that two distinctive features of WeChat, public account platform and group chat, support the formation of a public sphere: the public account platform functions as "a role of media outlet and allows mass audiences to receive some degree of shared text", "the group chat function facilitates some degree of public debate" (p.345). The two features foster new ways of engaging the public through bonding the solidarity of people who share the same interest, binding relationships between different groups, and linking people from different fields under a certain topic [85].

The aforementioned empirical research mainly discusses what social media platforms could offer to users either to maintain established cultural values or develop new ones. Hence, it can be argued that they are in line with cultural affordances of technology.

\subsection{Affordances of the Cultural}

Prior research shows that cultural values and meanings could shape users' motivation as well as practices on social media platforms [22, 23, 40, 41, 59, 79]. For example, Monteiro [59] contends that the pervasive selfie practices in India could be influenced by the long-lasting daily cultural practices called darshan, which embodies the belief that a worshiper can interact with god directly "through active visual and physical exchange" (p.1). Nonetheless, technological intervention "rarely interrupts or intervenes in the visual and material interaction of the traditional practice of worship" [59, p.103]. Sheldon, Herzfeldt and Rauschnabel [79] state that cultural values can predict ways of using hashtags on social media. Users from a more collective culture tend to use implicit hashtags that are inspirational and artistic to identify people who can interpret the message [79].

Comparably, Chen [15] states that traditional Chinese cultural concepts, such as filial piety, social ties/guanxi, and face/mianzi, still affect how young Chinese students use WeChat: "they could be seen to carry out filial piety by creating virtual co-presence with their parents on WeChat, .... they remained aware of the necessity to present themselves in the online environment according to their parents' expectations" (p.254). Chen, Shao and Zhi [16] state that the concept of face, which is "deeply rooted in Chinese culture and the daily social behavior of Chinese people", plays an important role of predicting users' behavior of disclosing location on WeChat (p.3). Users who have a stronger desire to gain face or fear losing face tend to share their locations on WeChat [16]. Yuan and Qiu [103] state that WeChat interface design is influenced primarily by western style, and more Chinese cultural factors could be included, such as the color style, fonts, and certain themes. 
The aforementioned research discusses how cultural values and meanings could influence people's ways of using and designing a social media platform. Arguably, it can be defined as affordances of the cultural.

\section{Conclusion}

By reviewing prior research on social media affordances and revisiting the original meaning of the notion, we argue that the cultural aspect of affordances should be included as part of affordances theory. To enrich the cultural perspective of affordances in the field of social media studies, we offer a novel definition of cultural affordances that include two layers. Cultural affordances of technology examine how social media could shape established and emerging cultural values. Affordances of the cultural explore how established cultural values can influence the design and ways of using social media. Several examples are provided to exemplify how this new definition can be applied in prior empirical studies. Similarly, we expect that the definition will be useful in designing and interpreting future studies.

\section{References}

[1] Albrechtsen, H., Hans HK Andersen, S. Bødker, Annelise M. Pejtersen, "Affordances in activity theory and cognitive systems engineering", Rapport Technique Riso, 2001.

[2] Bærentsen, K. B., and J. Trettvik, "An activity theory approach to affordance", In Proceedings of the second Nordic conference on Human-computer interaction, 2012, October, pp. 51-60.

[3] Bareither, C., and C. Bareither, "Doing Emotion through Digital Media: An Ethnographic Perspective on Media Practices and Emotional Affordances", Ethnologia Europaea 49(1), 2019.

[4] Barker, C., Cultural studies: Theory and Practice (5th edition), SAGE, 2016.

[5] Barley, S. R., "Technology as an occasion for structuring: Evidence from observations of CT scanners and the social order of radiology departments", Administrative science quarterly, 1986, pp. 78-108.

[6] Bijker, W. E., "The social construction of Bakelite: Toward a theory of invention. The social construction of technological systems", 1987, pp. 159-187.

[7] Blau, P. M., C. M. Falbe, W. McKinley, \& P. K. Tracy, "Technology and organization in manufacturing", Administrative Science Quarterly, 1976, pp. 20-40.

[8] Bloomfield, B.P., Latham, Y. \& Vurdubakis, T. (2010)

Bodies, technologies and action possibilities when is an affordance? Sociology, 44, 415-433.

[9] Bourdieu, P., "Structures, habitus, practices", The Logic of Practice, 1990, pp. 52-65.
[10] boyd, D, "Social network sites as networked publics: Affordances, dynamics, and implications", In A Networked Self, Routledge, 2010, pp. 47-66.

[11] Bradner, E., "Social affordances of computer-mediated communication technology: understanding adoption", In CHI'01 Extended Abstracts on Human Factors in Computing System, 2001, March, pp. 67-68.

[12] Brock, A., "From the blackhand side: Twitter as a cultural conversation", Journal of Broadcasting \& Electronic Media 56(4), 2012, pp. 529-549.

[13] Bucher, T., and A., Helmond, "The affordances of social media platforms", In J. Burgess, A. E. Marwick, and T. Poell, eds., The Sage Handbook of Social Media, Sage Publications, London, UK, 2018, pp. 233-253.

[14] Cesarino, L., "How social media affords populist politics: remarks on liminality based on the Brazilian case", Trabalhos em Linguística Aplicada 59(1), 2020, pp. 404-427.

[15] Chen, S., "Face, Social Ties and Positive Energy: An Analysis of Young Chinese WeChat Users' Reflections on Mediated Social Relations (Doctoral dissertation, University of Leicester)", 2018.

[16] Chen, S., B. Shao and K. Zhi, "Predictors of chinese users' location disclosure behavior: An empirical study on wechat", Information 9(9), 2018, pp. 219.

[17] Costa, E., "Affordances-in-practice: An ethnographic critique of social media logic and context collapse", New Media \& Society 20(10), 2018, pp. 3641-3656.

[18] DeLuca, K. M., E. Brunner., and Y. Sun, "Weibo, WeChat, and the Transformative Events of Environmental Activism on China's Wild Public Screens", International Journal of Communication, 2016, p. 10.

[19] Despret, V., "What would animals say if we asked the right questions?" Vol. 38, U of Minnesota Press, 2016.

[20] Dinsmore, B., "Contested affordances: teachers and students negotiating the classroom integration of mobile technology", Information, Communication \& Society 22(5), 2019, pp. 664-677.

[21] Dohn, N. B., "Affordances revisited: articulating a Merleau-Pontian view", International Journal of ComputerSupported Collaborative Learning 4(2), 2009, pp. 151-170.

[22] Dou, X., "The influence of cultures on SNS usage: Comparing Mixi in Japan and Facebook in the US", Public Relations Journal 5(4), 2011, pp. 1-16.

[23] Elmasry, M. H., P. J. Auter, and S.R. Peuchaud, "Facebook across cultures: A cross-cultural content analysis of Egyptian, Qatari, and American student Facebook pages", Journal of Middle East Media 358(3038), 2014, pp. 1-28

[24] Fayard, A. L., and J. Weeks, "Affordances for practice", Information and Organization 24(4), 2014, pp. 236-249.

[25] Gaver, W. W., "Technology affordances", In Proceedings of the SIGCHI conference on Human factors in computing systems, 1991 March, pp. 79-84.

[26] Graves, L., "The affordances of blogging: A case study in culture and technological effects", Journal of Communication Inquiry 31(4), 2007, pp. 331-346.

[27] Gibson, J., The Ecological Approach to Visual Perception, 17th pr., Psychology Press, New York, 2011, (Original work published in 1979).

[28] Gibbs, J. L., N. A. Rozaidi and J. Eisenberg, "Overcoming the 'ideology of openness': Probing the affordances of social media for organizational knowledge 
sharing", Journal of Computer-Mediated Communication 19(1), 2013, pp.102-120.

[29] Gramsci, A, and Q. Hoare, Selections from the Prison Notebooks, Lawrence and Wishart, London, 1971.

[30] Hall, S., "Cultural studies: Two paradigms", Media, Culture \& Society 2(1), 1980, p. 57

[31] Hall, S, "Gramsci's Relevance for the Study of Race and Ethnicity", Journal of Communication Inquiry 10(2), 1986, pp. 5-27.

[32] Haraway, D., "A cyborg manifesto: Science, technology, and socialist-feminism in the late 20th century", The International Handbook of Virtual Learning Environments Springer, Dordrecht, 2006, pp. 117-158.

[33] Hartson, R., "Cognitive, physical, sensory, and functional affordances in interaction design”, Behaviour \& Information Technology 22(5), 2003, pp. 315-338.

[34] Heidegger, M., The Question Concerning Technology Harper \& Row, New York, 1977, pp. 3-35.

[35] Hoggart, R., The Uses of Literacy, Transaction publishers, 1957.

[36] Holmes, K., M. Balnaves, and Y. Wang, "Red Bags and WeChat (Wēixìn): Online collectivism during massive Chinese cultural events", Global Media Journal: Australian Edition 9(1), 2015, pp. 15-26.

[37] Hutchby I, "Technologies, texts and affordances", Sociology 35(2), 2001, pp. 441-456.

[38] Hutchby, I., "Communicative affordances and participation frameworks in mediated interaction", Journal of Pragmatics 72, 2014, pp. 86-89.

[39] Johnson, R., "What is cultural studies anyway?" Social Text (16), 1986, pp. 38-80.

[40] Johansson, E., and G. Nygren, "Russian journalists and social media: Updated traditions and new challenges", Central European Journal of Communication 2(7), 2014, pp. 273-290. [41] Kim, Y., D. Sohn, and S.M. Choi, "Cultural difference in motivations for using social network sites: A comparative study of American and Korean college students", Computers in Human Behavior 27(1), 2011, pp. 365-372.

[42] Kitayama, S., B. Mesquita, and M. Karasawa, "Cultural affordances and emotional experience: socially engaging and disengaging emotions in Japan and the United States", Journal of Personality and Social Psychology 91(5), 2006, p.890.

[43] Kgatle, M. S. "Social media and religion: Missiological perspective on the link between Facebook and the emergence of prophetic churches in southern Africa", Verbum et Ecclesia 39(1), 2018, pp. 1-6.

[44] Kling, R., "Social analyses of computing: Theoretical perspectives in recent empirical research", ACM Computing Surveys (CSUR) 12(1), 1980, pp. 61-110.

[45] Kling, R., "Learning about information technologies and social change: The contribution of social informatics", The Information Society 16(3), 2000, pp. 217-232.

[46] Kreijns, K. (2004). Sociable CSCL environments. Social affordances, sociability, and social presence.

[47] Latour, B., "Reassembling the social. An introduction to actor-network-theory," Journal of Economic Sociology 14(2), 2013, pp. 73-87.

[48] Latour, B., Down to Earth: Politics in the New Climatic Regime, John Wiley \& Sons, 2018.
[49] Law, J., "Notes on the theory of the actor-network: Ordering, strategy, and heterogeneity", Systems Practice 5(4), 1992, pp. 379-393.

[50] Leaver, T., T. Highfield, and C. Abidin, Instagram: Visual Social Media Cultures, John Wiley \& Sons, 2020.

[51] Leifer, R., "Matching computer-based information systems with organizational structures", Mis Quarterly, 1988, pp. 63-73.

[52] Mack, L., "The Significance of Red Envelopes in Chinese Culture", ThoughtCo., https://www.thoughtco.com/chinesenew-year-red-envelope-687537, 2019 August 17 (accessed March 5, 2020).

[53] Marwick, A. E., and D. boyd, "I tweet honestly, I tweet passionately: Twitter users, context collapse, and the imagined audience", New Media \& Society 13(1), 2011, pp. 114-133.

[54] Mason, C. L., "Tinder and humanitarian hook-ups: The erotics of social media racism", Feminist Media Studies 16(5), 2016, pp. 822-837.

[55] Matamoros-Fernández, A., "Platformed racism: The mediation and circulation of an Australian race-based controversy on Twitter,Facebook and YouTube", Information, Communication \& Society 20 (6), 2017, pp. 930-946.

[56] McVeigh-Schultz, J., and N.K. Baym, "Thinking of you: Vernacular affordance in the context of the microsocial relationship app, Couple", Social Media+ Society 1(2), 2014. [57] Miller, V., "New media, networking and phatic culture", Convergence 14(4), 2008, pp. 387-400.

[58] Moe, H., "Comparing Platform 'Ranking Cultures' Across Languages: The Case of Islam on YouTube in Scandinavia”, Social Media+ Society 5(1), 2019.

[59] Monteiro, S., "'Welcome to selfiestan': identity and the networked gaze in Indian mobile media", Media, Culture \& Society 42(1), 2020, pp. 93-108.

[60] Morris, M., "Banality in cultural studies", Discourse 10(2), 1988, pp. 3-29.

[61] Murphie, A., and J. Potts, Culture and Technology, Macmillan International Higher Education, 2017.

[62] Murray, D. C, "Notes to self: the visual culture of selfies in the age of social media", Consumption Markets \& Culture 18(6), 2015, pp. 490-516.

[63] Negro, G., G. Balbi, and P. Bory, "The path to WeChat: How Tencent's culture shaped the most popular Chinese app, 1998-2011”, Global Media and Communication, 2020.

[64] Nagy, P., and G. Neff, "Imagined affordance: Reconstructing a keyword for communication theory", Social Media+ Society 1(2), 2015.

[65] Nelson, C., P.A. Treichler, L. Grossberg, "Cultural studies: An introduction”, Cultural Studies 1(5), 1992, pp. 119.

[66] Norman DA, "Affordance, conventions, and design", Interactions 6(3), 1999, pp. 38-43.

[67] Norman, D. (2013). The design of everyday things:

Revised and expanded edition. Basic books.

[68] Orlikowski, W. J., "The duality of technology: Rethinking the concept of technology in organizations", Organization Science 3(3), 1992, pp. 398-427.

[69] Orlikowski, W. J., "Using technology and constituting structures: A practice lens for studying technology in organizations", Organization Science 11(4), 2000, pp. 404-28. [70] Oshlyansky, L., H. Thimbleby, and P. Cairns, "Breaking affordance: culture as context", In Proceedings of the third 
Nordic conference on Human-computer interaction, ACM, 2004, October, pp. 81-84.

[71] Oshlyansky, L., "Cultural models in HCI: Hofstede, affordance and technology acceptance (Doctoral dissertation Swansea University)", 2007.

[72] Postigo, H., "The socio-technical architecture of digital labor: Converting play into YouTube money", New Media \& Society, 18(2), 2016, pp. 332-349.

[73] Ramstead, M. J., S.P. Veissière, and L.J. Kirmayer, "Cultural affordances: scaffolding local worlds through shared intentionality and regimes of attention", Frontiers in Psychology 7, 2016, p. 1090.

[74] Ran, X., Gao, Y., Zhang, Y., \& Shuai, Q. (2020). Understanding the Time-Limited Privacy Settings on WeChat Moments: A Text Mining Approach. In PACIS (p. 167).

[75] Retallack, H., J. Ringrose, and E. Lawrence, "“Fuck your body image': Teen girls' Twitter and Instagram feminism in and around school", In Learning Bodies, Springer, Singapore, 2016, pp. 85-103.

[76] Robey, D., Raymond, B., \& Anderson, C. (2012).

Theorizing information technology as a material artifact in information systems research. Materiality and organizing:

Social interaction in a technological world, 217-236.

[77] Sawyer, S., and M. Tyworth, M., "Social informatics: Principles, theory, and practice", In IFIP International Conference on Human Choice and Computers, Springer, Boston, MA, 2006, pp. 49-62.

[78] Schrock, A. R., "Communicative affordances of mobile media: Portability, availability, locatability, and multimediality", International Journal of Communication 9, 2015, p. 18.

[79] Sheldon, P., E. Herzfeldt, and P. A. Rauschnabel, "Culture and social media: the relationship between cultural values and hashtagging styles", Behaviour \& Information Technology 39(7), 2020, pp. 758-770.

[80] Slack, J. D. and J. M, Wise, "Cultural studies and Technology", The Handbook of New Media, 2002, pp. 485501.

[81] Slack J. D, and J. M. Wise, Culture + Technology: A Primer, Peter Lang, 2005.

[82] Solymosi, T., "Against representation: A brief introduction to cultural affordances", Human Affairs 23(4), 2013, pp. 594-605.

[83] Treem, J. W., and P.M. Leonardi, "Social media use in organizations: Exploring the affordances of visibility, editability, persistence, and association", Annals of the International Communication Association 36(1), 2013, p. 143. [84] Trepte, S., "Social media, privacy, and self-disclosure: The turbulence caused by social media's affordances", Social Media+ Society 1(1), 2015.

[85] Tu, F., "WeChat and civil society in China", Communication and the Public 1(3), 2016, pp. 343-350.

[86] Turner, G., British Cultural Studies: An Introduction. Psychology Press, 2003.

[87] Turner, P., and S. Turner, "An affordance-based framework for CVE evaluation", In People and Computers XVI-Memorable Yet Invisible, Springer, London, 2002, pp. 89-103).

[88] Turner, P., "Affordance as context", Interacting with Computers 17(6), 2005, pp. 787-800.
[89] Van Osch, W., \& Mendelson, O. (2011). A typology of affordances: Untangling sociomaterial interactions through video analysis.

[90] Vitak, J., and J. Kim, “'You can't block people offline' examining how Facebook's affordances shape the disclosure process", In Proceedings of the 17th ACM conference on Computer supported cooperative work \& social computing, 2014, February, pp. 461-474.

[91] Vodanovich, S., B. McKenna, and W. Cai, "Cultural values inherent in the design of social media platforms: A case study of WeChat", BLED, 2017.

[92] Wang, X., and B. Gu, "The communication design of WeChat: ideological as well as technical aspects of social media", Communication Design Quarterly Review 4(1), 2016, pp. 23-35.

[93] Wellman, B., "The social affordances of e-mail", SIGGROUP Bulletin 20(2), 1999, p. 63.

[94] Wellman, B., A. Quan-Haase, J. Boase, W. Chen, K. Hampton, I. Díaz, and K. Miyata, "The social affordances of the Internet for networked individualism", Journal of Computer-mediated Communication 8(3), 2003, JCMC834.

[95] Williams, R., "Communications technologies and social institutions", Contact: Human Communication and its History, 1981, pp. 225-238.

[96] Williams, R., Culture and Society, 1780-1950, Columbia University Press, 1983.

[97] Williams, R., "Television: Technology and cultural form”, Psychology Press, 2003.

[98] Williams, R., "Culture is ordinary", Cultural Theory: An Anthology, 2011, pp. 53-59, (original work published in 1958).

[99] Willis, P. E., and P. Willis, Learning to Labor: How Working Class Kids Get Working Class Jobs, Columbia University Press, 1981.

[100] Winner, L., The Whale and the Reactor: A Search for Limits in an Age of High Technology, University of Chicago Press, 2010.

[101] Wirth, K., "What's the Significance of Lunar New Year Red Envelopes?", Seattletimes, https://www.seattletimes.com/life/whats-the-significance-oflunar-new-year-red-envelopes/, 2017 January 25.

[102] Wise, J. M., "Welcome to your assemblage", Exploring Technology and Social Space, 1997, pp. 137-159.

[103] Yuan, X., and C. Qiu, "Introduction to WeChat Interface Design Localization", In 4th International Conference on Education, Language, Art and Intercultural Communication (ICELAIC 2017), Atlantis Press, 2017 December. [104] Zhao, Y., Liu, J., Tang, J., \& Zhu, Q. (2013, March). Conceptualizing perceived affordances in social media interaction design. In Aslib Proceedings. Emerald Group Publishing Limited.

[105] Zammuto, R. F., Griffith, T. L., Majchrzak, A., Dougherty, D. J., \& Faraj, S. (2007). Information technology and the changing fabric of organization. Organization science, 18(5), 749-762.

[106] Zheng, Y., \& Yu, A. (2016). Affordances of social media in collective action: the case of Free Lunch for Children in China. Information Systems Journal, 26(3), 289313. 